\title{
POSSIBILITY OF CLOUDLESS OPTICAL REMOTE SENSING IMAGES ACQUISITION STUDY BY USING METEOROLOGICAL SATELLITE OBSERVATIONS
}

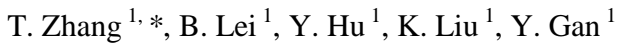 \\ ${ }^{1}$ Satellite Surveying and Mapping Application Center, National Administration of Surveying, Mapping and Geoinformation of China, \\ China - (zhangt, lb, huyz, liuk, ganyuhang)@ sasmac.cn
}

KEY WORDS: Cloud total amount, Cloudless image acquisition, Fengyun(FY) satellite, Ziyuan-3 (ZY-3) satellite

\begin{abstract}
:
Optical remote sensing images have been widely used in feature interpretation and geo-information extraction. All the fundamental applications of optical remote sensing, are greatly influenced by cloud coverage. Generally, the availability of cloudless images depends on the meteorological conditions for a given area. In this study, the cloud total amount (CTA) products of the Fengyun (FY) satellite were introduced to explore the meteorological changes in a year over China. The cloud information of CTA products were tested by using ZY-3 satellite images firstly. CTA products from 2006 to 2017 were used to get relatively reliable results. The window period of cloudless images acquisition for different areas in China was then determined. This research provides a feasible way to get the cloudless images acquisition window by using meteorological observations.
\end{abstract}

\section{INTRODUCTION}

For optical remote sensing, the cloud coverage is one of the most import factors that influence the satellite image quality. The cloud in the satellite image more or less covered the land surface information, resulting in hardly interpreting the land features from the image. Therefore, the cloudless images acquisition is a key issue for optical remote sensing promotion and application(Lee and Lin, 2016).

In recent years, China has conducted the first geographic conditions census to comprehensively grasp the status quo of physical geography and human geography. Majority of the geographic information in the census was extracted from optical remote sensing image of satellite (Zhang et al., 2016). Not only that, other important task in China, e.g., the national geographic conditions monitoring, fundamental surveying and mapping, emergency responses, are all in need of the capability of cloudless image acquisition.

The weather condition varies in different regions of China. Some of the south and north regions of China undergo rainy season or snowy season in the same month. The acquisition of cloudless optical remote sensing image changes spatially and temporally. The Fengyun (FY) satellites provide hourly continuous meteorological observations covering the whole China area, which is a potential way to grasp the meteorological changes over different regions in China. In this research, the cloud total amount (CTA) products of FY satellites were introduced to analyze the cloud spatial and temporal distributions. To get reliable results, the multi-year CTA products were tested by using Ziyuan-3 (ZY-3) satellite images firstly. The acquisition window period of cloudless satellite images was in turn to be determined.

\section{DATA}

\subsection{FY CTA products}

Since 1980s, China has constructed the meteorological satellite network, i.e., FY satellite network (Zhu et al., 2015). Currently, the network has launched over ten satellites. There are two types of meteorological satellites, including the polar orbiting meteorological satellites and the geostationary meteorological satellite. Generally, the geostationary meteorological satellite is located at certain longitude above the equator and provides hourly meteorological observations, (including cloud, aqueous vapour, etc.) over the whole China area by the visible and infrared spin scan radiometer (VISSR) sensor.

In this study, the CTA products from 2006 to 2017 of geostationary meteorological satellite, FY-2C, FY-2D, and FY$2 \mathrm{E}$, were used to analyze the cloud distribution in different regions and months. Many high-resolution satellites, e.g. ZY-3, Gaofen-1, Gaofen-2, cross through the equator at 10:30am local time. To guarantee the same acquisition time with many optical remote sensing satellites, the CTA products around the overpass time of those satellites were selected. The information of CTA products used in this study was listed in Table1.

\begin{tabular}{|c|c|c|c|c|}
\hline Satellite & Sensor & $\begin{array}{c}\text { Resolu } \\
\text { tion }\end{array}$ & Location & Time period \\
\hline FY-2C & VISSR & $5 \mathrm{~km}$ & $104.5^{\circ} \mathrm{E}$ & $2006.1 \sim 2009.11$ \\
FY-2D & VISSR & $5 \mathrm{~km}$ & $86.5^{\circ} \mathrm{E}$ & 2009.12 \\
FY-2E & VISSR & $5 \mathrm{~km}$ & $104.5^{\circ} \mathrm{E}$ & $2010.1-2015.6$ \\
FY-2E & VISSR & $5 \mathrm{~km}$ & $86.5^{\circ} \mathrm{E}$ & $2015.7-2017.12$ \\
\hline
\end{tabular}

Table 1. The information of CTA products of FY satellites

Figure 1 shows a cloud information sample of FY CTA products. The CTA is the area percentage of cloud in a pixel. It ranges from 0 to 1.0 , indicating clear and totally cloud covered area, respectively. The product is hierarchical data format (HDF) with the geostationary projection (NSMC, 2013).

\footnotetext{
* Corresponding author
} 


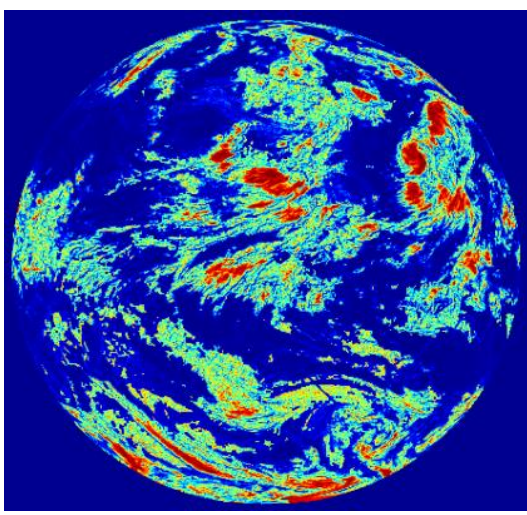

Figure 1. Image of FY-2E CTA products (Acquired at UTC time of 2:15am Jun. 8, 2016)

\subsection{ZY-3 images}

ZY-3 surveying satellite is the China's first civilian highresolution stereo mapping satellite, and is capable of providing high-resolution stereo and multi-spectral image (Tang et al., 2015). The satellite provides panchromatic image at 2.1-meter resolution (nadir), 3.6-meter (forward/backward) and multispectral image at 5.8-meter resolutions. Currently, there are two ZY-3 satellites were formed dual satellites network. The ZY-3 sensor calibration (SC level) image products were used to manually extract cloud areas to test the cloud amount of FY CTA products. Figure 2 has shown a sample of ZY-3 satellite images and manually extracted cloud areas. The grids indicate pixels of FY CTA products, and the values in each pixel are the manually extracted cloud amount within the pixel.

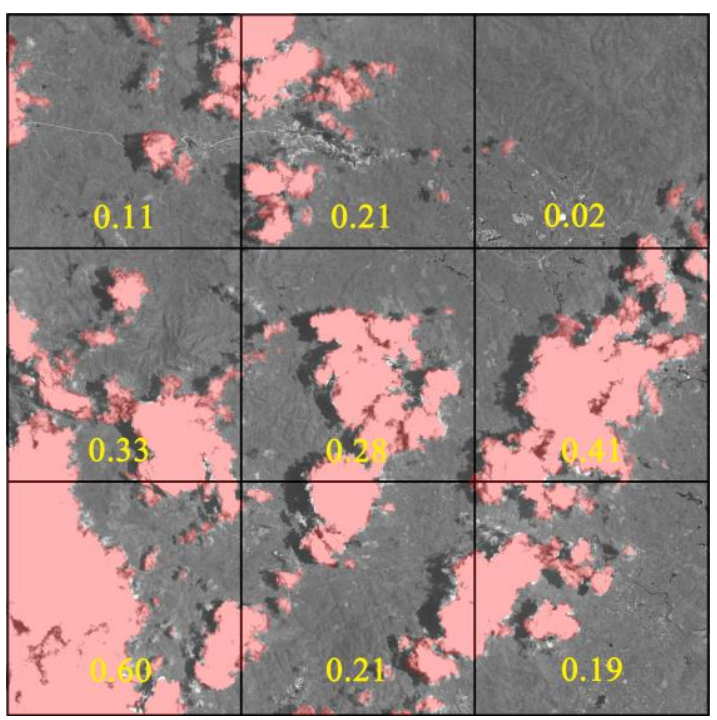

Figure 2. Sample of manually extracted cloud areas

\section{METHOD}

The FY CTA products were tested using manually extracted cloud areas from high resolution optical remote sensing image. The time-series CTA products were averaged to explore the temporal and spatial distribution of cloud. The widow periods of acquiring cloudless optical images in different regions were in turn to be determined according to cloud distribution analysis.

\subsection{Test of FY CTA products}

To guarantee the consistency of geographic coordinates between FY and ZY-3 satellite products, the FY CTA products was projected as equal latitude and longitude projections. The ZY-3 SC product was used to extract cloud areas manually. The FY products with the same time and areas with ZY-3 satellites observations were selected to test the precision of cloud amount.

\subsection{Analysis of cloud temporal and spatial distribution}

The CTA information of twelve years (from 2006 to 2017) was monthly averaged to get the averaged cloud total amount $(a C T A)$ for a given pixel.

$$
\begin{gathered}
C T A_{m}=\sum_{i=1}^{d} C T A_{i} / d \\
a C T A_{m}=\sum_{j=1}^{y}\left(C T A_{m, j}\right) / y \\
s C T A_{m}=\sqrt{\left(C T A_{m}-a C T A_{m}\right)^{2} / 12}
\end{gathered}
$$

where, $C T A_{m}, a C T A_{m}$, and $s C T A_{m}$ are monthly averaged CTA, yearly averaged CTA for each month, and standard deviation of yearly averaged CTA for each month, respectively. The $a C T A_{m}$ is expected to explore the cloud temporal and spatial distribution, and the ${ }_{S C T A_{m}}$ indicates the stability of cloud amount for each month in the twelve years. The lower the $s C T A_{m}$ is, the stability within the month

\section{RESULTS}

Figure 3 has shown the comparison of cloud amount between FY CTA products and artificial extractions. The root mean square error (RMSE) and correlation coefficient between these two results are $14.76 \%$ and 0.7898 , respectively. The cloud total amount of FY products has higher values than that from artificial extractions, as a whole. In addition, it was also found that some of snow was recognized as cloud in winter, especially in north and northwest regions of China.

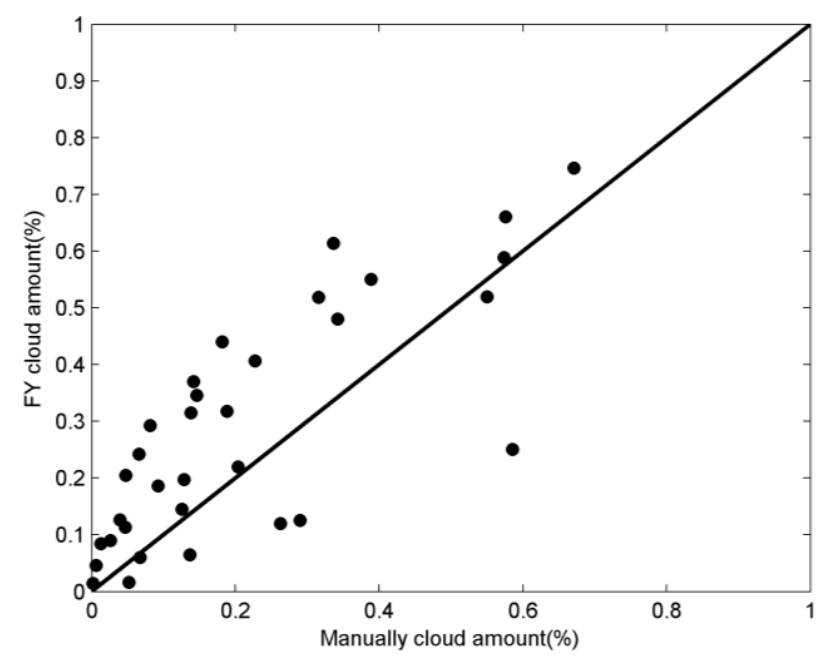

Figure 3. Comparison of cloud amount between FY CTA products and manually extractions

The spatial distribution of cloud total amount in China in different months has been shown in Figure 4. In addition, the 
standard deviation of yearly averaged CTA for each month has also been shown in Figure 5.
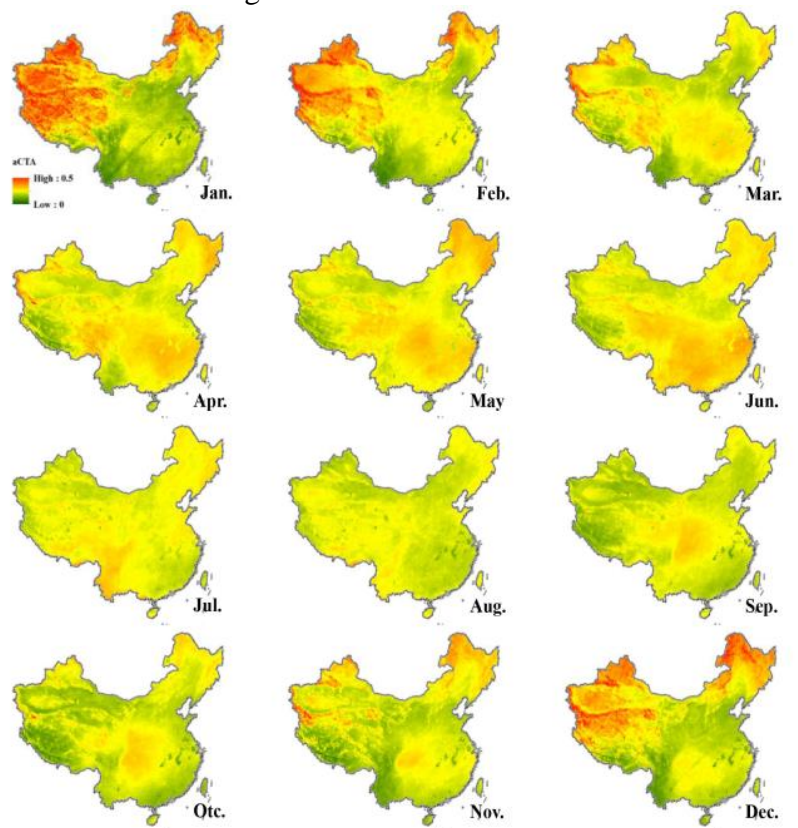

Figure 4. The spatial distribution of cloud total amount in China in different months
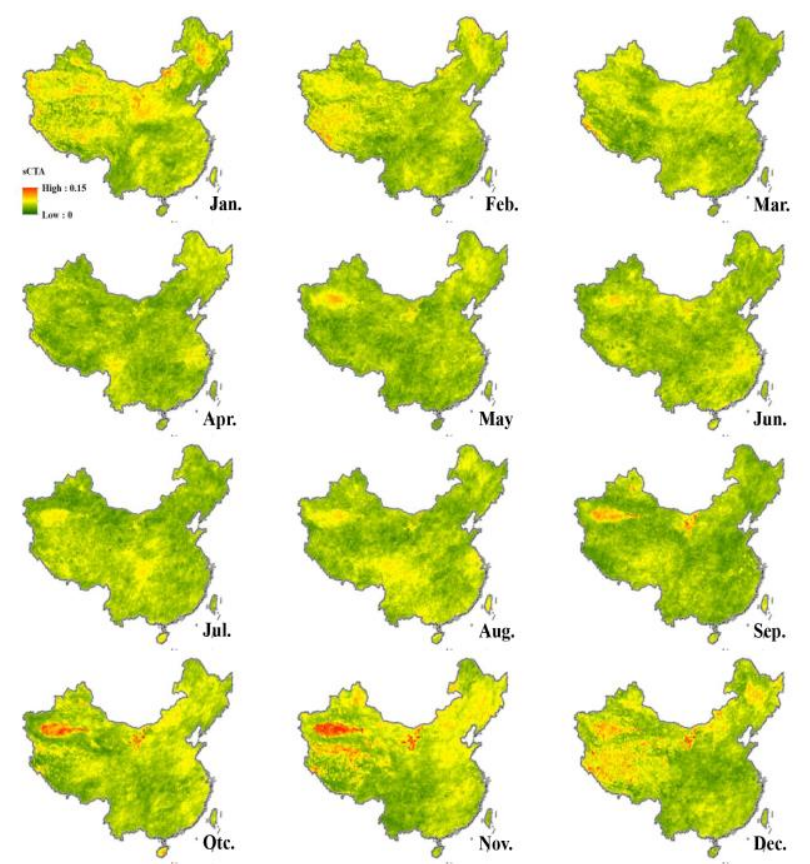

Figure 5. The standard deviation of cloud total amount in China in different months

The window period of cloudless images acquisition is the months in which both the averaged cloud total amount and the standard deviation are small. According to the spatial distribution and the standard deviation of cloud total amount in China, the window period of cloudless images acquisition was determined (Table 2). It also can be seen that the cloud total amount is relatively higher in winter than that in other months. The reason might be misclassification of snow as cloud in these areas in winter.

\begin{tabular}{|cc|}
\hline Area & $\begin{array}{c}\text { Window period of cloudless } \\
\text { images acquisition }\end{array}$ \\
\hline $\begin{array}{c}\text { Northeast } \\
\text { area } \\
\text { Northwest } \\
\text { area } \\
\text { Southeast } \\
\text { area }\end{array}$ & August and September \\
$\begin{array}{c}\text { Southwest } \\
\text { area } \\
\text { Center } \\
\text { area }\end{array}$ & From November and October \\
\end{tabular}

Table 2. The Window period of cloudless images acquisition for different areas in China

\section{CONCLUSION AND DISCUSSION}

In this study, the cloud total amount (CTA) products of the Fengyun (FY) satellite were introduced to explore the meteorological changes in a year over China. The cloud information of CTA products were tested by using ZY-3 satellite images before it was used to analyze the meteorological conditions. CTA products from 2006 to 2017 were used to get relatively reliable results. The window period of cloudless images acquisition for different areas in China was determined. This research provides a feasible way to get the cloudless images acquisition window by using meteorological observations. The future work is analysing the cloud distribution and window period of cloudless images acquisition for different provinces to support the national geographic conditions monitoring in different areas. In addition, more meteorological satellite observations are needed to get the global information of cloud distribution.

\section{ACKNOWLEDGEMENTS}

This work is supported by the National Key Research and Development Program of China (Grant NO.2016YFB0501403) and the Demonstration System of High-Resolution Remote Sensing Application in Surveying and Mapping of China.

\section{REFERENCES}

Lee, K. Y., Lin C. H., 2016. Cloud detection of optical satellite images using support vector machine, The International Archives of the Photogrammetry, Remote Sensing and Spatial Information Sciences, Prague, Czech Republic, Vol. XLI-B7, pp. 289-293.

National Satellite Meteorological Center(NSMC), 2013. FY-2 HDF5.0 File Format Specification (Version 3.0), http://satellite.nsmc.org.cn/PortalSite/Default.aspx.

Tang, X., Zhou, P., Zhang, G., Wang, X., Jiang Y., Guo, L., Liu, S.,2015. Verification of ZY-3 Satellite Imagery Geometric Accuracy Without Ground Control Points, IEEE Geoscience and Remote Sensing Letters, pp. 2100-2104.

Zhang, T., Lei, B., Gan, Y., Hu, Y. and Liu, K., 2016. National satellite image coverage using overall planning technique, 2016 IEEE International Geoscience and Remote Sensing Symposium (IGARSS), Beijing, pp. 5488-5491. 
The International Archives of the Photogrammetry, Remote Sensing and Spatial Information Sciences, Volume XLII-3, 2018 ISPRS TC III Mid-term Symposium "Developments, Technologies and Applications in Remote Sensing", 7-10 May, Beijing, China

Zhu, L., Wang, M., Shao, J., Liu, C., Zhao, C. and Zhao, Y., 2015. Remote sensing of global volcanic eruptions using Fengyun series satellites, 2015 IEEE International Geoscience and Remote Sensing Symposium (IGARSS), Milan, pp. 47974800 . 